PII: S0045-6535(98)00108-8

\title{
EFFECT OF LIQUD SEWAGE SLUDGE ADDITION ON ATRAZINE SORPTION AND DESORPTION BY SOIL
}

\author{
R. Celis, E. Barriuso ${ }^{\star}$ and S. Houot \\ Unité de Science du Sol, INRA. 78850 Thiverval-Grignon, B.P. 01, France
}

(Received in Germany 20 October 1997; accepted 20 March 1998)

\begin{abstract}
Liquid sewage sludge (LSS) addition to soil incorporates both insoluble suspended organic material and large amounts of dissolved organic matter (LSSDOM) which can influence the sorption-desorption behaviour of pesticides by soil constituents. Batch sorption isotherm techniques were used to determine the relative effect of the insoluble and dissolved organic matter from a LSS on the sorption and desorption of the herbicide atrazine by soil. Atrazine sorption and desorption isotherms were obtained on soil, LSS, LSS-amended soil, and LSSDOM-pretreated soil and described by the Freundlich equation. The overall effect of LSS addition to soil (insoluble and dissolved organic matter) was to increase atrazine sorption, due to the high sorption capacity of the added insoluble organic matter. In contrast, LSSDOM, which was mainly constituted by low molecular weight molecules, decreased atrazine sorption by the soil. No evidences for stable interactions in solution between LSSDOM and atrazine were found, thus suggesting processes taking place at the soil/solution interface, such as competition for sorption sites on the soil surface, are the main responsible for the observed decrease in atrazine sorption by LSSDOM. Desorption of atrazine from soil was also enhanced by LSSDOM, but this effect was highly reduced when the soil had been pretreated with LSS (insoluble and soluble organic matter) or with LSSDOM alone. In these cases, interactions of LSSDOM with the soil surface have already taken place before the desorption experiment and the LSSDOM effects during desorption are less evident. The results of this work suggest that LSSDOM applied to soils may enhance the risk of groundwater contamination by promoting atrazine desorption from soil, especially when the soil surfaces are free of LSSDOM. ㅇ 1998 Published by Elsevier Science Ltd. All rights reserved
\end{abstract}

\section{INTRODUCTION}

Application of municipal sewage sludge to soil and irrigation with reclaimed waste waters are common practices in many countries. Advanced wastewater treatment enables irrigation with treated sewage as means for disposal and pollution control, and as an alternative source for water and nutrients [1-5]. Sewage sludges have been shown to improve soil physical structure, water holding capacity and organic matter (OM) composition; however, some environmental problems may also occur because of their trace metal contamination [6-8]. Thus, the rates and frequency of the application of sludges and 
wastewater are usually calculated in terms of nutrient release, nitrate leaching and water contamination or in terms of heavy metal content to avoid heavy metals accumulation in soil, but these calculations do not take into account the effect of these amendments on other compounds such as pesticides.

Sorption of many pesticides, especially the nonionic pesticides, is controlled by the soil OM content [9]. Organic amendment addition to soil increases the soil OM content and thus may greatly affect pesticide sorption-desorption processes [10]. It is generally accepted that the incorporation of insoluble OM from organic amendments to the soil enhances pesticide sorption [10-12]; however, organic amendments can also produce dissolved organic matter (DOM) whose effect on pesticide sorption is by far less understood. Even less is known about how this DOM influences the desorption of chemicals previously adsorbed on soils. DOM can reduce pesticide sorption, or increase desorption, by stable interactions in solution or by competing with the pesticide molecules from sorption sites on the soil surface, but it may also promote pesticide sorption by the increase of soil $\mathrm{C}$ content via adsorption of some DOM fractions on the soil [13].

Liquid sewage sludges contain both insoluble and dissolved organic materials and are characterized by their large water content which makes the role of the DOM especially important as compared to other organic wastes. The objective of this work was to evaluate the effects of liquid sewage sludge addition to soil on the sorption-desorption behaviour of the herbicide atrazine with special relevance to the relative effect of the insoluble and dissolved organic matter on the sorption-desorption processes.

\section{MATERIALS AND METHODS}

\section{Materials}

Atrazine (2-chloro-4-ethylamino-6-isopropylamino-1,3,5-triazine) was purchased from Amersham (Les Ulis, France). The molecule was ${ }^{14} \mathrm{C}$-labelled and had specific activity of $710^{8} \mathrm{~Bq} \mathrm{mmol}{ }^{-1}$ and radiopurity $>98.8 \%$.

The soil used was a Typic Eutrochrept located at Grignon (France). It was sampled in the surface layer $(0-20 \mathrm{~cm})$, air-dried and sieved $(<2 \mathrm{~mm})$ prior to use. It had a pH of 7.2 with $220 \mathrm{~g} \mathrm{~kg}^{-1}$ of clay, $730 \mathrm{~g}$ $\mathrm{kg}^{-1}$ of silt, $11.7 \mathrm{~g} \mathrm{~kg}^{-1}$ of organic $\mathrm{C}$ and $1.3 \mathrm{~g} \mathrm{~kg}^{-1}$ of organic $\mathrm{N}$.

The liquid sewage sludge (LSS) was the anaerobically digested product collected from the municipal sewage plant of Plaisir (France). It contained both insoluble and dissolved organic materials. The insoluble material was $25.0 \mathrm{~g}$ dry matter per liter of the initial sludge suspension and contained $294 \mathrm{~g}$ organic $\mathrm{C} \mathrm{kg}^{-1}$ and $47.4 \mathrm{~g}$ organic $\mathrm{N} \mathrm{kg}^{-1}$. The DOM solution from the LSS (LSSDOM) was obtained by centrifugation at $10000 \mathrm{~g}$ for $30 \mathrm{~min}$ using a Sorval RC-5B centrifuge (DuPont Co., Newtown, CT). LSSDOM was usually used immediately after preparation or stored at $3^{\circ} \mathrm{C}$ with no chemical additives. The LSSDOM extract was discarded if not used within $48 \mathrm{~h}$ from the time of preparation. 
The $\mathrm{pH}$ of the LSSDOM was 7.5, its soluble organic $\mathrm{C}$ content was $1058 \mathrm{mg} \mathrm{L}^{-1}$, and its electrical conductivity was $5.8 \mathrm{mdS} \mathrm{m}^{-1}$.

\section{Atraxine sorption-desorption studies}

Sorption of atrazine on soil, sludge, and sludge-amended soil. Atrazine sorption isotherms on soil, on the insoluble matter of LSS, and on LSS-amended soil were obtained by the batch equilibration procedure using $25-\mathrm{mL}$ Corex glass centrifuge tubes with Teflon caps. Sorption isotherms were obtained on $3 \mathrm{~g}$ of soil, $5 \mathrm{~mL}$ of LSS (containing $0.125 \mathrm{~g}$ dry matter), and $3 \mathrm{~g}$ of soil amended with 1,2 and $5 \mathrm{~mL}$ of LSS $(9,18$, and $45 \mathrm{~g}$ of LSS dry matter per $\mathrm{kg}$ soil, respectively). After adding $0.01 \mathrm{M}$ $\mathrm{CaCl}_{2}$ solution, when necessary, to a final volume of $5 \mathrm{~mL}$, all suspensions were pre-equlilibrated by shaking for $24 \mathrm{~h}$ at $20 \pm 2{ }^{\circ} \mathrm{C}$ and then, $1 \mathrm{~mL}$ of ring-labelled ${ }^{14} \mathrm{C}$-atrazine water solution ( $400 \mathrm{~Bq} \mathrm{~mL}^{-1}$ ) at different herbicide concentrations was added, allowing to obtain atrazine concentrations ranging between 0.5 and $5 \mathrm{mg} \mathrm{L}^{-1}$. Dissolved organic $\mathrm{C}$ (DOC) and $\mathrm{pH}$ were measured on blank samples just before herbicide addition. After atrazine was added, suspensions were shaken at $20 \pm 2^{\circ} \mathrm{C}$ for other 24 $h$ and then the supernatants were recuperated by centrifugation and their radioactivity determined with a Kontron Betamatic liquid scintillation counter (Kontron Instr., Montigny le Bretonneux, France). Amounts of herbicide sorbed for each initial concentration were obtained by comparing the radioactivity measurements in $0.5 \mathrm{~mL}$ of supernatant solution with that of $0.5 \mathrm{~mL}$ of blank solution (prepared without solid but otherwise handled identically). Amounts of sorbed herbicide were always expressed on a dry weight basis.

Atrazine sorption on soil in presence of LSSDOM. The effect of the LSSDOM on atrazine sorption by soil was studied by pre-equilibrating at $20 \pm 2^{\circ} \mathrm{C}(24 \mathrm{~h}) 3 \mathrm{~g}$ of soil with $5 \mathrm{~mL}$ of LSSDOM instead 0.01 $\mathrm{M} \mathrm{CaCl}_{2}$ solution. After pre-equilibration, atrazine was added, suspensions were shaken for other $24 \mathrm{~h}$, and sorbed herbicide determined as above.

Atrazine desorption studies. Atrazine desorption was measured after sorption using the highest equilibrium concentration of the sorption isotherms. The $3 \mathrm{~mL}$ of supernatant removed for the sorption analysis were replaced with $3 \mathrm{~mL}$ of either $0.01 \mathrm{M} \mathrm{CaCl}_{2}$ or LSSDOM solution. After shaking at $20 \pm$ $2{ }^{\circ} \mathrm{C}$ for $24 \mathrm{~h}$, the suspensions were centrifuged and atrazine concentration determined in the supernatant as described above. This desorption procedure was repeated four times. All sorptiondesorption experiments were run in duplicate.

Sorption-desorption isotherms were fit to the logarithmic form of the Freundlich equation:

$$
\log C_{s}=\log \mathrm{K}_{f}+\mathrm{nf} \log \mathrm{C}_{e} \quad \text { Eq. (1) }
$$

were $C_{s}\left(\mathrm{mg} \mathrm{kg}^{-1}\right)$ is the amount of herbicide sorbed at the equilibrium concentration $\mathrm{C}_{e}\left(\mathrm{mg} \mathrm{L}^{-1}\right)$, and $\mathrm{K}_{f}$ and $\mathrm{nf}$ are the empirical Freundlich coefficients. 


\section{Equilibrium dialysis method}

The extent of interaction in solution between the LSSDOM and atrazine was determined using an equilibrium dialysis technique. Four mililiters of freshly prepared LSSDOM solution containing $3 \mathbf{m g ~ L}$ ${ }^{1}$ of ${ }^{14} \mathrm{C}$-atrazine was shaken for $24 \mathrm{~h}$ at $20 \pm 2{ }^{\circ} \mathrm{C}$, and then dialyzed against $4 \mathrm{~mL}$ water for other $24 \mathrm{~h}$ at the same temperature using a Dianorm equilibrium dialysis system (Dianorm, Munich). In this system, a semipermeable membrane of molecular weight cutoff of 5000 Daltons (Dianorm, Munich) separes a $10 \mathrm{~mL}$-teflon dialysis cell into two halves. The $4 \mathrm{~mL}$ of LSSDOM-atrazine solution was injected into one half-cell and the $4 \mathrm{~mL}$ of water into the other. After $24 \mathrm{~h}$ of mechanical shaking of the cell (12 rpm), atrazine concentration in the two halves was determined by liquid scintillation counting. Preliminary experiments had revealed that $24 \mathrm{~h}$ was sufficient to reach the dialysis equilibrium for atrazine. The amount of LSSDOM-associated atrazine can be determined from the difference in the herbicide concentrations at both sides of the dialysis membrane.

\section{Molecular size analysis of LSSDOM}

Three methods were compared for LSSDOM molecular size analysis: gel filtration (GF), highperformance size exclusion chromatography (HPLC-SEC), and dialysis separation (DS).

The gel filtration method was performed on a $1.8 \mathrm{i} . \mathrm{d}$. $\times 25 \mathrm{~cm}$ long chromatographic glass column packed with a Sephadex G-25 gel. The void volume $\left(\mathrm{V}_{\mathrm{o}}\right)$ and total permeation volume $\left(\mathrm{V}_{\nu}\right)$ of the column were determined with Blue Dextran ( $0.2 \%)$ and $0.1 \mathrm{M} \mathrm{NaCl}$, respectively. The exclusion limit of Sephadex G-25 gel is 5000 Daltons for spheric molecules such as globular proteins [14]. Molecules with molecular weight above the exclusion limit of the gel are totally excluded from the gel and eluted at the void volume, $V_{\mathrm{o}}$. LSSDOM was chromatographed by applying $2 \mathrm{~mL}$ of solution to the top of the column and eluted with distilled water [15] at a flow rate of $2.4 \mathrm{~mL} \mathrm{~min}^{-1}$. Organic substances were detected at $254 \mathrm{~nm}$ using a Perkin-Elmer, model Lambda 5, UV-Visible spectrophotometer equiped with a continous flow cell.

High performance size exclusion chromatography was performed using a $7.8 \mathrm{~mm}$ i.d. $\times 30 \mathrm{~cm}$ long, porous silica column (Protein Pak 60, Waters, MW separation range 600-8000 Daltons) connected to a Waters 600 E HPLC system controller and a Waters 996 photodiode array detector set at $254 \mathrm{~nm}$. After conditioning the column with distilled water, $0.1 \mathrm{~mL}$ of LSSDOM was injected and eluted at a flow rate of $1 \mathrm{~mL} \mathrm{~min}{ }^{-1}$. The void and total permeation volumes were determined with Blue Dextrane $(0.2 \%)$ and $0.1 \mathrm{M} \mathrm{NaCl}$, respectively. UV absorbance at the void volume of the gel was related to molecules with molecular size $>5000$ Daltons.

Dialysis of LSSDOM against water was carried out using the same system described above for determining the extent of interaction between the LSSDOM and atrazine. Four mililiters of LSSDOM were dialyzed against four mililiters of water using a semipermeable membrane of molecular weight cutoff of 5000 Daltons (Dianorm, Munich). Organic carbon at each side of the membrane was 
determined (Dohrmann Carbon-Analyzer DC-80), and the difference was assumed to correspond to molecules with molecular size $>5000$ Daltons.

\section{RESULTS AND DISCUSSION}

\section{Atrazine sorption on soil, sludge, and sludge-amended soil}

Sorption of atrazine on soil and LSS. Atrazine sorption isotherms on Grignon soil and LSS are shown in Fig. 1. Sorption measured in LSS can be attributed to its insoluble fraction, that is, the centrifuged pellets separated before the measurement of atrazine equilibrium concentration in solution. The corresponding sorption coefficients, $K_{f}$ and $n_{p}$ obtained by fitting the sorption data to the Freundlich equation (Eq. 1) are reported in Table 1. The analysis of the $n_{f}$ sorption coefficients indicates L-type ( $n_{f}$ $<1$ ) atrazine sorption isotherm on soil, according to the Giles et al. [16] classification, and C-type ( $\mathrm{nf}=$ 1) sorption isotherm for LSS. The L-type isotherm found for atrazine sorption on soil may suggest minimum competition with water molecules for sorption sites on soil and saturation of the solid with the herbicide at highest atrazine concentrations [16-18]. The C-type isotherm found for atrazine sorption on LSS is compatible with retention of the herbicide by partitioning into the bulk of the insoluble organic matter of LSS [19]. Figure 1 shows the high sorption of atrazine on the insoluble organic matter of LSS compared with that on Grignon soil, the $\mathrm{K} f$ value for atrazine sorption on LSS being about twenty times higher than that for soil (Table 1). This suggests that low amounts of LSS may greatly influence atrazine sorption when added to this soil relatively poor in organic matter.

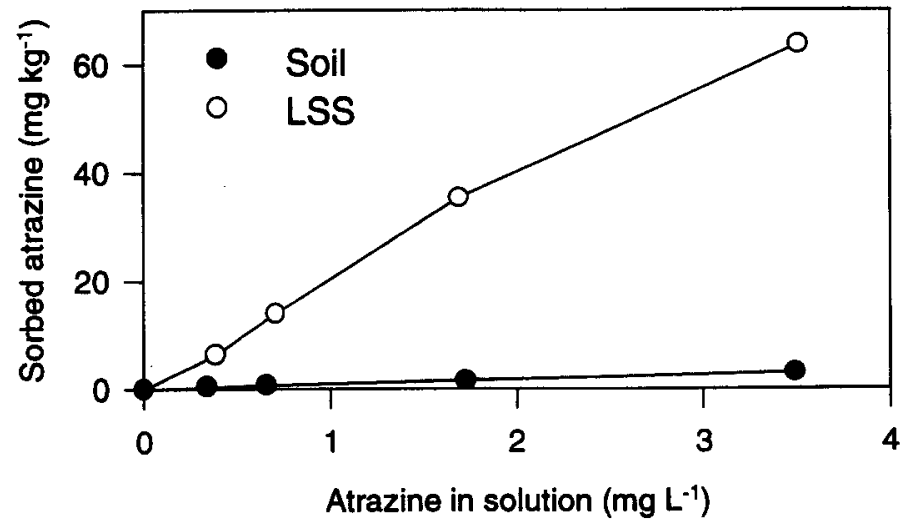

Figure 1. Atrazine sorption isotherms on Grignon soil and the insoluble fraction of LSS. 
Table 1. Atrazine sorption coefficients, $\mathrm{pH}$ values, and dissolved and solid-phase organic $\mathrm{C}$ content for soil, LSS, and LSS-amended soil.

\begin{tabular}{|c|c|c|c|c|c|c|}
\hline Sorbent & $\mathrm{pH}$ & $\begin{array}{c}\text { Solid-phase } \\
\text { organic C } \\
\left(\mathrm{g} \mathrm{kg}^{\prime}\right)\end{array}$ & $\begin{array}{c}\mathrm{DOC} \\
\left.(\mathrm{mg} \mathrm{L})^{-1}\right)\end{array}$ & nf & Kf & Koc \\
\hline Soil & 7.2 & 11.7 & $10 \pm 2$ & $0.85 \pm 0.03$ & $1.00 \pm 0.03$ & 85 \\
\hline LSS-amended soil $\left(9 \mathrm{~g} \mathrm{~kg}^{-1}\right)$ & 7.2 & 14.2 & $52 \pm 8$ & $0.96 \pm 0.03$ & $1.01 \pm 0.02$ & 71 \\
\hline LSS-amended soil $\left(18 \mathrm{~g} \mathrm{~kg}^{-1}\right)$ & 7.2 & 16.7 & $140 \pm 2$ & $0.98 \pm 0.01$ & $1.06 \pm 0.01$ & 63 \\
\hline LSS-amended soil ( $45 \mathrm{~g} \mathrm{~kg}^{\prime}$ ) & 7.2 & 23.8 & $487 \pm 39$ & $0.89 \pm 0.02$ & $1.49 \pm 0.02$ & 63 \\
\hline LSS & 7.3 & 294 & $958 \pm 4$ & $1.04 \pm 0.07$ & $18.7 \pm 1.1$ & 64 \\
\hline
\end{tabular}

The effectiveness of the organic $\mathrm{C}$ of soil and LSS in sorbing atrazine can be compared by normalizing the Freundlich sorption coefficients, $K_{f}$, to the respective organic $C$ contents $\left(K_{o c}\right)$. As shown in Table $1, K_{o c}$ of soil was even higher than that of the LSS insoluble organic matter. This may suggest that the effectiveness of the organic $\mathrm{C}$ of soil is higher than that of the insoluble fraction of LSS; however, contribution of mineral constituents to atrazine sorption by soil could also explain the difference in $\mathrm{K}_{\mathrm{oc}}$ values for soil and LSS.

Sorption of atrazine on LSS-amended soil. Atrazine sorption isotherms on soil amended with different amounts of LSS (insoluble + dissolved material) are shown in Fig. 2. In Table 1 are reported the corresponding Freundlich coefficients together with the $\mathrm{pH}$ values, and the dissolved and solid-phase organic $\mathrm{C}$ contents for the different mixtures. It should be noted that LSS addition increased both the $\mathrm{C}$ content of soil and the DOC in solution but did not change the $\mathrm{pH}$. The $\mathrm{n}_{\mathrm{f}}$ atrazine sorption coefficients increased by LSS addition whereas $\mathrm{K}_{\mathrm{oc}}$ values decreased, both becoming closer to the value obtained for LSS alone (Table 1), thus indicating the contribution of LSS to the retention of atrazine.

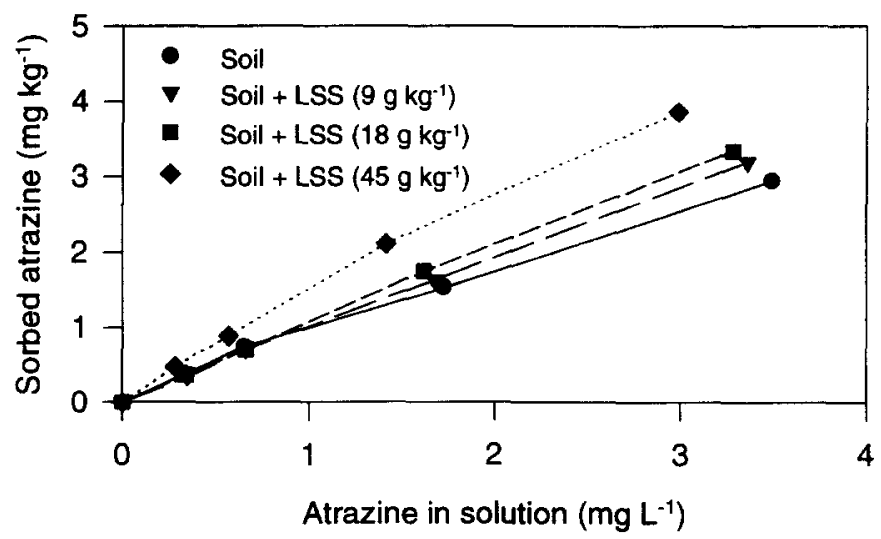

Figure 2. Atrazine sorption isotherms on soil amended with different amounts of LSS. 
LSS addition significantly increased atrazine sorption by the soil, especially at higher herbicide concentrations (Fig. 2). The increase in pesticide sorption by organic amendment addition to soil has been previously reported by several authors and attributed to the high sorptive capacity of the insoluble organic matter added to the soil [10,12,20-22]. It could be interesting, however, to compare the experimental sorption isotherms measured for the different soil-LSS mixtures with the corresponding sorption isotherms calculated assuming an independent sorption behaviour for the soil and LSS in the mixtures. These isotherms can be calculated as follows:

The total amount of herbicide sorbed by a soil-LSS mixture is given by

$$
C_{\text {stotal }}=C_{\text {s-soil }} \cdot(1-\theta)+C_{\text {s-Lss }} \cdot \theta \quad \text { Eq. (2) }
$$

where $\mathrm{C}_{\text {s-total }}$ is the total amount of atrazine $\left(\mathrm{mg} \mathrm{kg}^{-1}\right)$ sorbed by the mixture, $\mathrm{C}_{\text {s-soil }}$ and $\mathrm{C}_{\text {s-Lss }}$ are the relative amounts of atrazine ( $\mathrm{mg} \mathrm{kg}^{-1}$ ) sorbed by the soil and LSS, respectively, and $\theta$ is the fraction of LSS in the mixture.

If we consider an independent sorption behaviour for the soil and LSS, individual Freundlich equations will be followed:

$$
\begin{array}{cc}
\mathrm{C}_{s-\text {-ooil }}=\mathrm{K}_{\text {f-soil }} \cdot \mathrm{Ce}^{\mathrm{nf-soil}} & \text { Eq. (3) } \\
\mathrm{C}_{\text {s-Lss }}=\mathrm{K}_{f-L s s} \cdot \mathrm{Ce}^{\mathrm{nf-Lss}} & \text { Eq. (4) }
\end{array}
$$

Substituting Eq. 3 and 4 for Cs-soil and Cs-ss, respectively, in Eq. 2 the amount of atrazine sorbed by the soil-LSS mixture for a given equilibrium concentration can be directly calculated from the individual sorption coefficients and the fraction of LSS in the mixture by

$$
\mathrm{C}_{\text {s-total }}=\mathrm{Kf}_{\text {-soil }} \cdot(1-\theta) \cdot \mathrm{Ce}^{\mathrm{nf-soil}}+\mathrm{Kf}_{\mathrm{f}-\mathrm{LS}} \cdot \boldsymbol{\theta} \cdot \mathrm{Ce}^{\mathrm{nf} \text {-Lss }} \text { Eq. (5) }
$$

Atrazine sorption isotherms calculated using Eq. 5 for the different soil-LSS mixtures are compared in Fig. 3 with the corresponding measured sorption isotherms. It is worthy to note that, despite the observed increase of the experimental $\mathrm{K}_{f}$ value with increasing amounts of added LSS, the experimental $\mathrm{K}_{f}$ coefficients are only $\mathbf{8 0 - 8 7} \%$ of the expected values, Kf-alc, calculated assuming an independent sorptive behaviour for the soil and LSS in the mixtures (Fig. 3). This indicates that the effectiveness of soil and LSS in sorbing atrazine is lower in the soil-LSS mixtures than in the isolated systems. This can be explained by interactions between the soil and the organic matter of LSS that could result in some blockage of sorption sites for atrazine on both soil and LSS. Moreover, the presence of DOM from LSS (LSSDOM) could also reduce atrazine sorption on soil through stable interactions in solution or by processes taking place at the soil/solution interface, such as competition for sorption sites on the soil surface [13,23]. In fact, DOC measured in the supernatant of the soil-LSS mixtures before atrazine addition (Table 1 ) were only $25-50 \%$ of the initially added DOC, indicating that much of the LSSDOM is sorbed by the soil. Figure 4 shows the amounts of LSSDOM sorbed on soil against the LSSDOM 


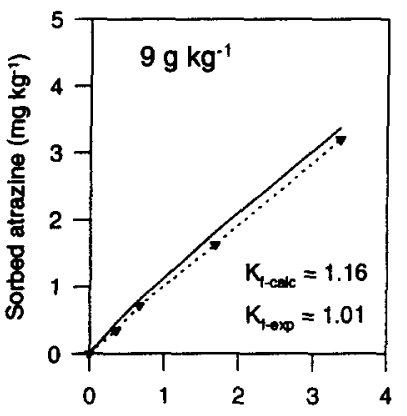

Atrazine in solution (mg L-1)

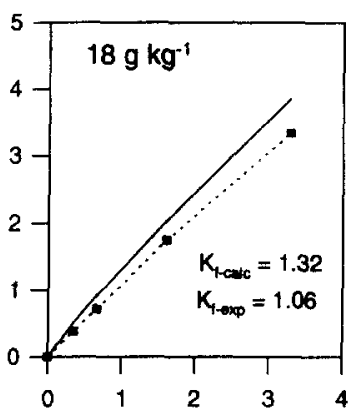

Atrazine in solution $\left(\mathrm{mg} \mathrm{L}^{-1}\right)$

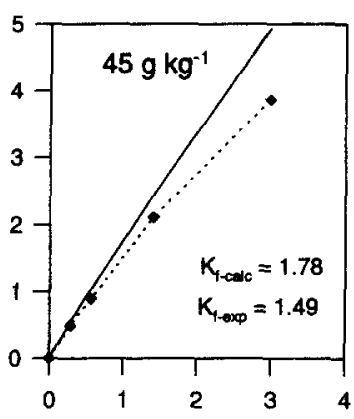

Atrazine in solution (mg L-1)

Figure 3. Experimental (symbols) and calculated (solid lines) atrazine sorption isotherms for the different soil-LSS mixtures. Calculated sorption isotherms were obtained considering independing sorption behaviour for the soil and LSS.

remaining in solution for the three soil-LSS mixtures. The shape of the resulting sorption isotherm, Ltype according to the Giles et al. [16] classification, indicates progressive saturation of the soil with LSSDOM with increasing amounts of added LSS. This LSSDOM sorption on soil could result in some reduction of the affinity of the soil surface for atrazine, for instance by blockage of sorption sites for the herbicide, thus reducing the sorption capacity of the soil and partially obscuring the positive effect of the insoluble organic material in the systems amended with LSS.

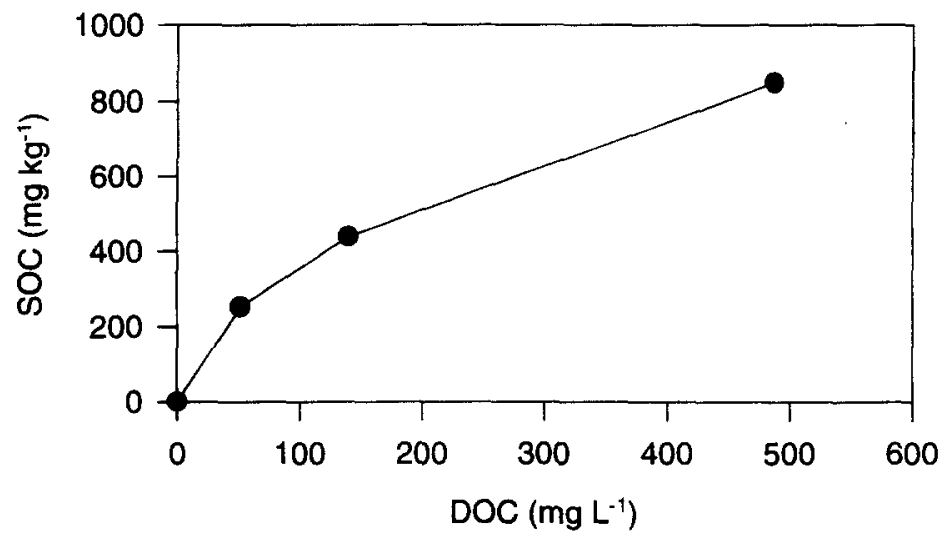

Figure 4. Sorption isotherm of LSSDOM on soil. SOC: sorbed organic C DOC: dissolved organic $\mathrm{C}$. 


\section{Effect of LSSDOM on atrazine sorption by soil}

The relative effect of the dissolved organic matter present in LSS on atrazine sorption by soil was evaluated by comparing the sorptive behaviour of the soil pre-equilibrated with LSSDOM with that of the soil pre-equilibrated with $0.01 \mathrm{M} \mathrm{CaCl}_{2}$, used as a reference. The amount of added LSSDOM corresponded to the highest amount of LSS used in the soil-LSS mixtures. Sorption isotherms are shown in Fig. 5. LSSDOM alone reduced atrazine sorption, in contrast with the whole LSS which increased herbicide sorption. LSSDOM reduced the $\mathrm{Kf}$ value of atrazine sorption on soil from 1.00 obtained in $\mathrm{CaCl}_{2}$ to 0.83 (Table 2). This reduction in sorption coincided with the difference observed in Fig. 3 between the measured and calculated $\mathrm{K}_{f}$ values obtained when the whole LSS, insoluble and soluble organic material, was added to the soil (Kfexp for the soil-LSS mixture with the highest amount of LSS was $84 \%$ of $\mathrm{K}_{\text {f-alc). }}$. This suggested the DOM present in LSS may be the main responsible for the differences reported in Fig. 3 between the experimental and calculated $\mathrm{K}_{\mathrm{f}}$ values for the soil-LSS mixtures.

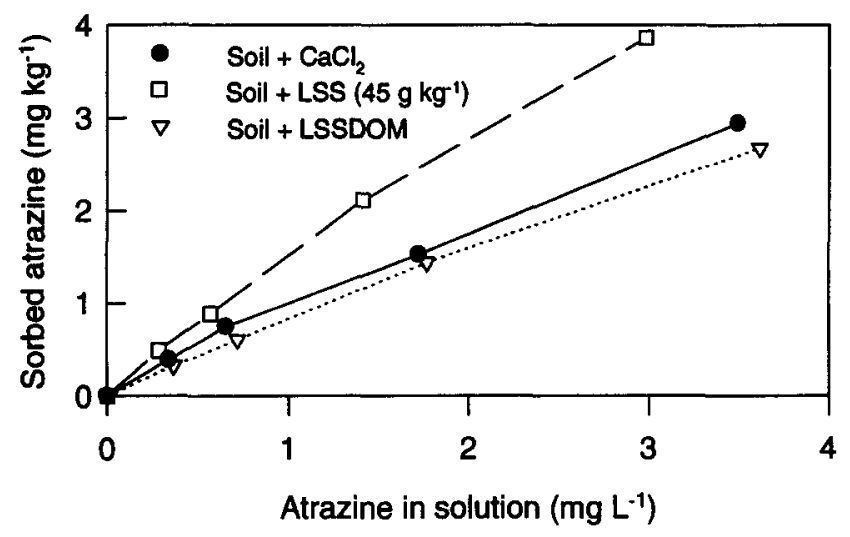

Figure 5. Atrazine sorption isothems on soil pre-equilibrated with $\mathrm{CaCl}_{2}$, LSS (insoluble and soluble organic matter), and LSSDOM alone corresponding to the amount added in LSS.

Table 2. Atrazine sorption coefficients, $\mathrm{pH}$ values, and dissolved and solid-phase organic $\mathrm{C}$ content for soil pre-equilibrated with $\mathrm{CaCl}_{2}, \mathrm{LSS}$, and LSSDOM alone.

\begin{tabular}{lcccccc}
\hline Sorbent & $\mathrm{pH}$ & $\begin{array}{c}\text { Solid-phase } \\
\text { organic } \mathrm{C}^{*} \\
\left(\mathrm{~g} \mathrm{~kg}^{-1}\right)\end{array}$ & $\begin{array}{c}\text { DOC } \\
\left(\mathrm{mg} \mathrm{L}^{-1}\right)\end{array}$ & nf & Kf & $\mathrm{K}_{\mathrm{oc}}$ \\
\hline Soil + $\mathrm{CaCl}_{2}$ & 7.2 & 11.7 & $10 \pm 2$ & $\mathbf{0 . 8 5} \pm 0.03$ & $1.00 \pm 0.03$ & $\mathbf{8 5}$ \\
Soil + LSSDOM & 7.5 & 12.4 & $559 \pm 1$ & $0.92 \pm 0.01$ & $0.83 \pm 0.01$ & 67 \\
Soil + LSS $\left(45 \mathrm{~g} \mathrm{~kg}^{-1}\right)$ & 7.2 & 24.5 & $487 \pm 39$ & $0.89 \pm 0.02$ & $1.49 \pm 0.02$ & 61 \\
\hline
\end{tabular}

\footnotetext{
* Taking into account the amounts of LSSDOM sorbed on soil.
} 
Table 3. Percentages of $\mathrm{C}$ corresponding to the fractions with molecular weights below and above 5000 Daltons in LSSDOM estimated by gel permeation (GP), high-performance size exclusion chromatography (HPLC-SEC) and dialysis separation (DS).

\begin{tabular}{lcc}
\hline Method & \multicolumn{2}{c}{$\%$} \\
& $<5000 \mathrm{Da}$ & $>5000 \mathrm{Da}$ \\
\hline GP (ABS 254 mm) & 85 & 15 \\
HPLC-SEC (ABS 254 nm) & 78 & 22 \\
DS (DOC) & 79 & 21 \\
\hline
\end{tabular}

The association of DOM with organic compounds in the solution phase has been proposed as the principal process which can reduce the sorption of organic compounds by solid sorbents [23-25]; however, DOM can also reduce pesticide sorption by processes taking place at the soil/solution interface, such as competition for sorption sites on the soil surface $[10,13,23]$. Sorption of DOM on soil may also modify the charge characteristics or the hydrophobic/hydrophilic character of the soil surface, thus changing its affinity for a given pesticide. The extent of interaction between LSSDOM and atrazine in the solution phase was determined in this work by the equilibrium dialysis method using a semipermeable membrane of 5000 Daltons. No differences were found between the atrazine concentrations at both sides of the dialysis membrane which indicated lack of interaction between atrazine and the fraction of molecules larger than 5000 Daltons present in LSSDOM. Molecular weight analysis of LSSDOM showed that only about $20 \%$ of LSSDOM corresponded to macromolecules with MW> 5000 Daltons (Table 3). Low MW molecules are supposed to have even less degree of association with pesticides than that of larger ones [26]. This suggested that such proportion of macromolecules was not enough to develop clear evidences of interactions in solution between atrazine and LSSDOM or that the principal mechanism by which LSSDOM reduces atrazine sorption on soil could involve processes at the soil/solution interface more than stable interactions in solution. The latter hypothesis was further supported by the desorption results reported in the next section.

Figure 6 shows the several processes which may be involved in atrazine sorption on soil in the presence of LSSDOM. They include LSSDOM-atrazine interactions in solution, LSSDOM-atrazine interactions at the soil/solution interface, and soil-atrazine interactions. Distribution coefficients, $\mathrm{K}$, can be defined for each of these processes assuming linear sorption (Fig. 6). The apparent distribution coefficient, $K_{a p}$, for atrazine (AT) sorption on soil measured in the presence of LSSDOM is given by

$$
\mathrm{K}_{\mathrm{ap}}=\frac{\text { Total sorbed AT }\left(\mathrm{mg} \mathrm{kg}^{-1} \text { soil }\right)}{\text { Total AT in solution }\left(\mathrm{mg} \mathrm{L}^{-1}\right)}=\frac{\mathrm{C}_{s}+\mathrm{Cs}^{\prime} \cdot \mathrm{C}_{\mathrm{soc}}}{\mathrm{C}_{\mathrm{e}}+\mathrm{C}_{e^{\prime}} \cdot \mathrm{C}_{\mathrm{doc}}} \quad \text { Eq. (6) }
$$

where $\mathrm{C}_{\mathrm{s}}\left(\mathrm{mg} \mathrm{kg}^{-1}\right.$ soil ) is the amount of atrazine actually sorbed on soil, $\mathrm{C}_{\mathrm{s}}{ }^{\prime}\left(\mathrm{mg} \mathrm{kg}^{-1} \mathrm{C}\right)$ is the amount of atrazine sorbed on the LSSDOM associated with the soil surface (SOC), $\mathrm{C}_{\mathrm{soc}}\left(\mathrm{kg} \mathrm{C} \mathrm{kg}^{-1}\right.$ soil) is the amount of LSSDOM associated with the soil, $\mathrm{C}_{\mathrm{e}}\left(\mathrm{mg} \mathrm{L}^{-1}\right)$ is the concentration of free-atrazine in solution, $\mathrm{C}_{\mathrm{e}}{ }^{\prime}\left(\mathrm{mg} \mathrm{kg}^{-1} \mathrm{C}\right)$ is the amount of atrazine bound to LSSDOM in solution and $\mathrm{C}_{\mathrm{doc}}\left(\mathrm{kg} \mathrm{C} \mathrm{L}^{-1}\right)$ is the concentration of LSSDOM in solution. 


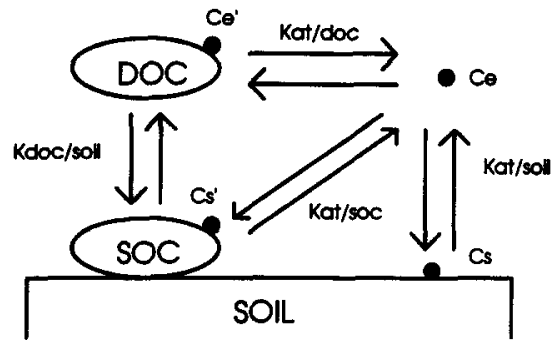

Figure 6. Scheme of atrazine sorption by soll in the presence of LSSDOM.

DOC: Dissolved organic $C$ at concentration Cdoc; SOC: Sorbed organic C at concentration Csoc.

Substituting $\mathrm{C}_{\mathrm{s}}^{\prime}$ and $\mathrm{C}_{\mathrm{e}}^{\prime}$ for $\mathrm{K}_{\mathrm{at} / \mathrm{soc}} \cdot \mathrm{C}_{\mathrm{e}}$ and $\mathrm{K}_{\mathrm{at} / \mathrm{doc}} \cdot \mathrm{C}_{\mathrm{e}}$, respectively, in $\mathrm{Eq}$. 6 the apparent sorption coefficient can be expressed as

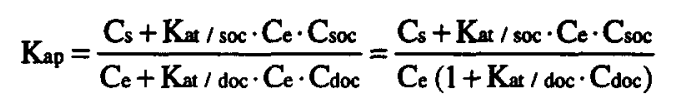

Since $\mathrm{C}_{\mathrm{s}} / \mathrm{C}_{\mathrm{e}}=\mathrm{K}_{\mathrm{at} / \mathrm{soi}}$ and $\mathrm{C}_{\mathrm{woc}}=\mathrm{K}_{\mathrm{doc} / \mathrm{soil}} \cdot \mathrm{C}_{\mathrm{doc}}$, it follows that

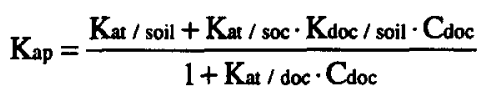

This equation is similar to that reported by Rav-Acha and Rebhun [27] to evaluate pesticide sorption by clay in the presence of dissolved humic acid, although these authors considered that atrazine had the same affinity for the humic acid associated with the clay as that for the dissolved humic acid in solution, that is $\mathrm{K}_{\mathrm{a} / \mathrm{soc}}=\mathrm{K}_{\mathrm{avdoc}}$. Using Eq. 8, it is possible to estimate the partition coefficient for atrazine on the LSSDOM associated with the soil (SOC), $\mathrm{K}_{\mathrm{at} / \mathrm{soc}}$, from

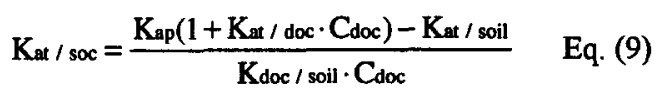

Assuming that, as evidenced by the dialysis experiments, interactions in solution are not important $\left(\mathrm{K}_{\mathrm{at} / \mathrm{doc}} \cdot \mathrm{C}_{\mathrm{doc}} \ll 1\right)$, it follows that the effect of LSSDOM on atrazine sorption by soil will be due to 
sorption of this LSSDOM on the soil and we can calculate the distribution coefficient for atrazine on the SOC from

$$
K_{\text {at } / \text { soc }}=\frac{K_{\text {ap }}-K_{\text {at } / \text { soil }}}{K_{\text {doc } / \text { soil }} \cdot C_{d o c}} \quad \text { Eq. (10) }
$$

In the above expression $\mathrm{K}_{\mathrm{ap}}$ and $\mathrm{K}_{\mathrm{at} / \mathrm{soil}}$ are the atrazine sorption coefficients measured in the presence and absence of LSSDOM, respectively, and the product $K_{\text {doc/soil }} \cdot C_{d o c}$ represents the amount of LSSDOM sorbed on soil. Thus, from the values measured in this work of $\mathrm{K}_{\mathrm{ap}}=0.83 \mathrm{~L} \mathrm{~kg}^{-1}, \mathrm{~K}_{\mathrm{at} / \text { soil }}=$ $1.00 \mathrm{~L} \mathrm{~kg}^{-1}$, and the value of $\mathrm{K}_{\text {doc/soil }} \mathrm{C}_{\mathrm{doc}}=7.0610^{-4} \mathrm{~kg} \mathrm{C} \mathrm{kg}^{-1}$ soil obtained from the sorption isotherm in Fig. 4, we obtain a value for $\mathrm{K}_{\mathrm{at} / \mathrm{soc}}=-240 \mathrm{~L} \mathrm{~kg}^{-1} \mathrm{C}$. This value can be considered as a measure of the negative effect of LSSDOM association with the soil surface on atrazine sorption by the soil. As mentioned above, this negative effect can be attributed not only to direct blockage of sorption sites for atrazine by the sorbed LSSDOM but also to some modification of the surface characteristics resulting in decreased affinity for the pesticide molecule. For instance, binding of LSSDOM to soil could take place through hydrophobic regions of LSSDOM with the hydrophilic and ionizable groups oriented to the solution. This would make the soil/solution interface more hydrophilic leading to preferential sorption of water molecules instead of hydrophobic compounds, such as atrazine.

\section{Desorption experiments}

Atrazine sorption-desorption isotherms by LSS and by soil pre-equilibrated with $\mathrm{CaCl}_{2}, \mathrm{LSS}$, and LSSDOM using $\mathrm{CaCl}_{2}$ and LSSDOM for the desorption steps are shown in Fig. 7. Freundlich parameters for desorption isotherms, $\mathrm{K}_{\mathrm{fd}}$, are given in Table 4 . In this table are also given the hysteresis coefficients, $\mathrm{H}$, calculated according to:

$$
\mathrm{H}=\mathrm{n}_{\mathrm{f} \text { des }} / \mathrm{n}_{\mathrm{f}-\mathrm{ads}} \quad \text { Eq. }(11)
$$

where $\mathrm{n}_{\mathrm{f}-\mathrm{ads}}$ and $\mathrm{n}_{\mathrm{f} \text {-des }}$ are the Freundlich $\mathrm{n}_{\mathrm{f}}$ constants obtained from the sorption and desorption data, respectively $[10,28,29]$.

Table 4. Freundlich desorption parameters, Kfd, and hysteresis coefficients, $\mathrm{H}$, for LSS, and for soil pre-equilibrated with $\mathrm{CaCl}_{2}$, LSS, and LSSDOM using $\mathrm{CaCl}_{2}$ and $\mathrm{LSSDOM}$ as desorbing solutions.

\begin{tabular}{lccccc}
\hline Sorbent & \multicolumn{2}{c}{$\mathrm{K}_{\mathrm{fd}}$} & & \multicolumn{2}{c}{$\mathrm{H}\left(\mathrm{n}_{\mathrm{fd}} / \mathrm{n}_{\mathrm{f}}\right)$} \\
& $\mathrm{CaCl}_{2}$ & LSSDOM & & $\mathrm{CaCl}_{2}$ & LSSDOM \\
\hline LSS & $30.6 \pm 1.0$ & $31.7 \pm 0.8$ & & 0.50 & 0.50 \\
CaCl $_{2}$-preequilibrated soil & $1.68 \pm 0.02$ & $1.41 \pm 0.03$ & 0.50 & 0.67 \\
LSS-preequilibrated soil (45 $\left.\mathrm{g} \mathrm{kg}^{-1}\right)$ & $1.88 \pm 0.04$ & $1.68 \pm 0.02$ & & 0.71 & 0.83 \\
LSSDOM-preequilibrated soil & $1.36 \pm 0.04$ & $1.25 \pm 0.02$ & & 0.59 & 0.71 \\
\hline
\end{tabular}



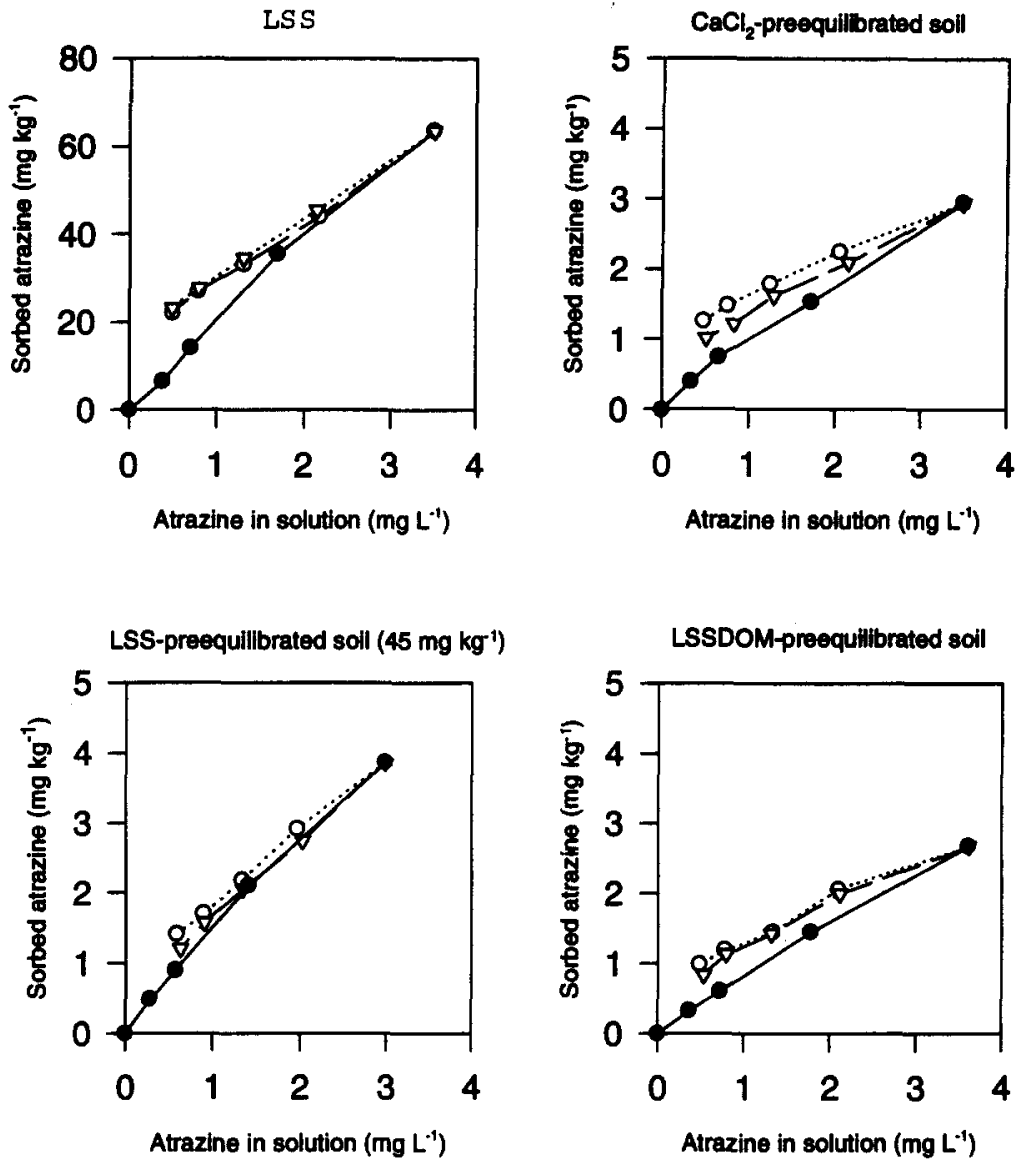

Figure 7. Atrazine sorption-desorption isotherms by LSS and $\mathrm{CaCl}_{2}-$, LSSand LSSDOM-preequilibrated soil:

- Adsorption $\odot$ Desorption with $\mathrm{CaCl}_{2} \quad \nabla \quad$ Desorption with LSSDOM.

Atrazine sorption-desorption was hysteretic in all systems $(\mathrm{H}<1)$, but some differences in the desorption behaviour were found when LSSDOM was used instead of $\mathrm{CaCl}_{2}$ solution for the desorption of the previously adsorbed atrazine (Fig. 7, Table 4). While no differences were found between $\mathrm{CaCl}_{2}$ and LSSDOM in desorbing atrazine from LSS, in the case of soil the LSSDOM solution showed a greater desorption capability than $\mathrm{CaCl}_{2}$, as indicated by the lower $\mathrm{K} f d$ constants (decreasing from 1.68 to 1.41 ) and by the higher $\mathrm{H}$ coefficients (increasing from 0.50 to 0.67 ) (Table 4). In the case of LSS- and LSSDOM-preequilibrated soil, LSSDOM was aiso more effective than $\mathrm{CaCl}_{2}$ in extracting sorbed atrazine, but Fig. 7 clearly shows that, compared to soil alone, differences were reduced to a great extent. 
The greater capability of LSSDOM compared to $0.01 \mathrm{M} \mathrm{CaCl}_{2}$ in desorbing atrazine from soil agrees with the negative effect of LSSDOM in atrazine sorption on soil and could be explained either by stable interactions in solution between LSSDOM and atrazine or by processes taking place at the soil/solution interface such as competition for sorption sites on soil. Nevertheless, the fact that no differences between $\mathrm{CaCl}_{2}$ and LSSDOM were found for atrazine desorption from LSS suggested that interactions in solutions were not important, since LSSDOM-atrazine interactions in solution would be also operative in the case of LSS. This was corroborated by the observation that differences in desorption with LSSDOM and $\mathrm{CaCl}_{2}$ were significantly reduced for LSS- and LSSDOM-preequlibrated soil (Fig. 7). For these systems, association of LSSDOM with the soil surface has already taken place before the desorption experiment and the LSSDOM effects during desorption are less evident. It should also be noted that in these systems (LSS- and LSSDOM-treated soil) the hysteresis coefficients for atrazine desorption using $\mathrm{CaCl}_{2}$ were higher than the corresponding value obtained for the untreated soil (Table 4). It is possible that LSSDOM sorption on soil blocked the most energetic sites for atrazine, so that atrazine sorption was restricted to sites where the retention force was weaker and from which the desorption was easier $[10,13,30]$.

\section{CONCLUSIONS}

The incorporation of insoluble and soluble organic matter to soil by liquid sewage sludge addition influences atrazine sorption-desorption behaviour in soil. The results of this work showed that the overall effect of LSS addition to soil was to increase atrazine sorption, due to the high sorption capacity of the added insoluble organic matter. Dissolved organic materials, which were constituted by $80 \%$ of low molecular weight fraction ( $<5000$ Daltons), decreased herbicide sorption on soil and partially obscured the role of the insoluble organic matter in enhancing herbide sorption. Dissolved organic matter from LSS also enhanced the desorption of the atrazine previously sorbed on soil; however, this effect was not observed for atrazine desorption from LSS alone and was highly reduced when the soil had been pretreated with LSSDOM. These data suggested that processes taking place at the soil/solution interface, such as competition between LSSDOM and atrazine for sorption sites, more than stable interactions in solution, was the principal mechanism by which LSSDOM reduced sorption and enhanced atrazine desorption by soil. No readsorption of the desorbed atrazine on soil exogenous organic matter (sorbed LSSDOM) seemed to occur. It is suggested that the risk of groundwater contamination by enhanced atrazine desorption due to LSSDOM will be especially important in newly amended soils but will be progressively reduced as the soil surfaces become covered by the added LSSDOM.

\section{ACKNOWLEDGMENT}

This work has been partially supported by Association Franco-Israelienne pour la Recherche Scientifique et Technologique (AFIRST). R. Celis thanks the Spanish Ministry of Education and Science for his PFPI fellowship. 


\section{REFERENCES}

1. R. N. Cromer, D. Tompkins, N. J. Barr and P. Hopmans, Irrigation of Montery pine with wastewater: effect on soil chemistry and groundwater composition, J. Environ. Qual., 13, 539-542 (1984).

2. B. Fattal, Y. Wax and M. Davis, Health risks associated with wastewater irrigation: an epidemiological study, Amer. J. Public Health, 76, $977-979$ (1986).

3. G. Oron, Y. DeMalach, Z. Hoffman, Y. Keren, H. Hartmann and N. Planer, Wastewater disposal by sub-surface trickle irrigation, Proceedings of 15th Biennal Conference of the IAWPRC, pp. 21492158. Kyoto Japan (1990).

4. E. R. Graber, Z. Gerstl, E. Fischer and U. Mingelgrin, Enhanced transport of atrazine under irrigation with effluent, Soil Sci. Soc. Am. J., 59, 1513-1519 (1995).

5. T. Asano and R. A. Mills, Planning and analysis for water reuse projects, Amer. Wat. Works Assoc., 1, 38-47 (1996).

6. M. B. Levine, A. T. Hall, G. W. Barrett and D. H. Taylor, Heavy metal concentrations during ten years of sludge treatment to an old-field community, J. Environ. Qual., 18, 411-418 (1989).

7. J. Baham and G. Sposito, Adsorption of dissolved organic carbon extracted from sewage sludge on montmorillonite and kaolinite in the presence of metal ions, J. Environ. Qual., 23, 147-153 (1994).

8. S. Brown, R. Chaney and J. S. Angle, Subsurface liming and metal movement in soils amended with lime-stabilized biosolids, J. Environ. Qual., 26, 724-732 (1997).

9. J. W. Hamaker and J. M. Thompson, Adsorption, In Organic Chemicals in the Soil Environment (Edited by Goring and Hamaker), p. 49-143. Marcel Dekker, New York (1972)

10. D. Businelly, Pig slurry amendment and herbicide coapplication effects on s-triazine mobility in soil: an adsorption-desorption study, J. Environ. Qual., 26, 102-108 (1997).

11. J. J. Hassett and W. L. Banwart, The sorption of nonpolar organics by soils and sediments, In Reactions and Movement of Organic Chemicals in Soils (Edited by B.L. Sawheney and K. Brown), p. 31-44. SSSA, Madison, WI (1989).

12. C. A. Bellin, G. A. O'Connor and Y. Jin, Sorption and degradation of pentachlorophenol in sludge-amended soils, J. Environ. Qual., 19, 603-608 (1990). 
13. E. Barriuso, U. Baer and R. Calvet, Dissolved organic matter and adsorption-desorption of dimefuron, atrazine, and carbetamide by soils, J. Environ. Qual., 21, 359-367 (1992).

14. T. G. Cooper, The Tools of Biochemistry, John Wiley \& Sons, New York (1977).

15. L. Dunemann and G. Schwedt, Zur analytic von elementbindungsformen in bodenslösungen mit gel-chromatographie und chemischen reaktionsdektoren, Soil and Sewage Sludges, 317, 394-399 (1984).

16. C. H. Giles, T. H. Mac Ewan, S. N. Kakhwa and D. Smith, Studies in adsorption. Part XI. A system of classification of solution adsorption isotherms, and its use in diagnosis of adsorption mechanisms and in measurement of specific surface areas of solids, J. Chem. Soc., 3973-3993 (1960).

17. O. P. Bansal, Adsorption of oxamyl and dimecron in montmorillonite suspensions, Soil Sci. Soc. Am. J., 47, 877-883 (1983).

18. C. Moreau and C. Mouvet, Sorption and desorption of atrazine, deethylatrazine, and hydroxyatrazine by soil and aquifer solids, J. Environ. Qual., 26, 416-424 (1997).

19. C. T. Chiou, P. E. Porter and D. W. Schmedding, Partition equilibra of nonionic organic compounds between soil organic matter and water, Environ. Sci. Technol., 17, 227-231 (1983).

20. K. Schellenberg, C. Leuenberger and R. P. Schwarzenbach, Sorption of chlorophenols by natural sediments and aquifer materials, Environ. Sci. Technol., 18, 652-657 (1984).

21. M. J. Martinez-Iñigo and G. Almendros, Pesticide sorption on soils treated with evergreen oak biomass at different humification stages, Comm. Soil Sci. Plant Anal., 23, 1717-1729 (1992).

22. L. Guo, T. J. Bicki, A. S. Felsot and T. D. Hinesly, Sorption and movement of alachlor in soil modified by carbon-rich wastes, J. Environ. Qual., 22, 186-194 (1993).

23. D. -Y. Lee, W. J. Farmer and Y. Aochi, Sorption of napropamide on clay and soil in the presence of dissolved organic matter, J. Environ. Qual., 19, 567-573 (1990).

24. C. W. Carter and I. H. Suffet, Binding of DDT to dissolved humic materials, Environ. Sci. Technol., 16, 735-740 (1982).

25. G. Caron, I. H. Suffet and T. Belton, Effect of dissolved organic carbon on the environmental distribution of nonpolar organic compounds, Chemosphere 14, 993-1000 (1985) 
26. D. -Y. Lee and W. J. Farmer, Dissolved organic matter interaction with napropamide and four other nonionic pesticides, J. Environ. Qual., 18, 468-474 (1989).

27. Ch. Rav-Acha and M. Rebhun, Binding of organic solutes to dissolved humic substances and its effects on adsorption and transport in the aquatic environment, Wat. Res., 26, 1645-1654 (1992).

28. G. A. O'Connor, P. J. Wierenga, H. H. Cheng and K. G. Doxtader, Movement of 2,4,5-T through large soil columns, Soil Sci., 130, 157-162 (1980).

29. E. Barriuso, D. A. Laird, W. C. Koskinen and R. H. Dowdy, Atrazine desorption from smectites, Soil Sci. Soc. Am. J., 58, 1632-1638 (1994).

30. M. A. Locke, Sorption-desorption kinetics of alachlor in surface soil from two soybean tillage systems, J. Environ. Qual., 21, 558-566 (1992). 